\title{
Analysis of Distribution of Selected Bioactive Compounds in Camelina sativa from Seeds to Pomace and Oil
}

\author{
Danuta Kurasiak-Popowska ${ }^{1, * \mathbb{D}}$, Bernadetta Ryńska ${ }^{1}$ and Kinga Stuper-Szablewska ${ }^{2}$ \\ 1 Department of Genetics and Plant Breeding, Faculty of Agronomy and Bioengineering, Poznan University of \\ Life Sciences, Dojazd 11, 60-632 Poznań, Poland; rynbenia@gmail.com \\ 2 Department of Chemistry, Faculty of Wood Technology, Poznan University of Life Sciences, Wojska \\ Polskiego 75, 60-625 Poznań, Poland; kinga.stuper@up.poznan.pl \\ * Correspondence: danuta.kurasiak-popowska@up.poznan.pl; Tel.: +48-602-712-429
}

Received: 19 February 2019; Accepted: 24 March 2019; Published: 29 March 2019

\begin{abstract}
Camelina sativa is an oilseed plant that produces seed oil rich in vitamins, UFA (unsaturated fatty acids), phytosterols, and polyphenols. Most, but not all, bioactive compounds are soluble in oil. So far, studies have been based analyzing the profile of bioactive compounds only in oil. As part of this work, it was decided to examine the seeds, oil, and pomace of four genotypes of Camelina sativa (three spring genotypes and one winter cultivar). The transmission of bioactive compounds to oil and pomace was compared to their content in seeds. The quantitative profile of selected bioactive compounds was analyzed: eight flavonoid aglycons, 11 phenolic acids, three carotenoids, and 19 fatty acids. As a result of pressing more than $80 \%$ of flavonoids entered oil, whereas $20 \%$ remained in the pomace. When the content of phenolic acids in seeds and in oil was compared, it turned out that on average $50 \%$ of these compounds entered oil. Among all the phenolic acids under analysis the highest contents of chlorogenic, caffeic, and sinapic acids were found both in camelina seeds and oil. Similarly to the other bioactive compounds, more than $70 \%$ of fat-soluble carotenoids were extracted from camelina seeds with oil. Most of the genotypes had the fatty acid composition and the $\omega-6 / \omega-3$ ratio characteristic of camelina oil. Camelina oil is characterized by properties that enable its extensive use in the food industry.
\end{abstract}

Keywords: Camelina sativa; bioactive compounds; seed; pomace; oil

\section{Introduction}

In recent years the consumption of vegetable fats has been increasing systematically due to the promotion of a balanced diet, which includes functional food as an important element. These significant changes in the consumption of fats result not only from economic factors (changes in income and prices of food) and consumers' new preferences, but also from the higher demand for oil and margarine in secondary processing (for the production of highly processed food and biofuels) [1].

At present, cold-pressed oils are the most popular vegetable fats consumed in Poland because of their health-promoting values. Rapeseed, sunflower, and linseed oils are traditionally produced and used in Poland. Recently consumers have been searching for a variety of tastes and health-promoting products. Consequently, there has been increasing interest in oils made from the seeds of other plants. One of which is camelina oil, a traditional product made from cold-pressed Camelina sativa seeds. Camelina sativa is an annual oilseed plant of the Brassicaceae family. It has been used for oil production for 3000 years. The increasing interest in camelina oil results from the fact that it contains large amounts of essential unsaturated fatty acids (UFA), i.e., $\omega-6$ fatty acid (linoleic acid) and $\omega-3$ fatty acid (linolenic acid) [2]. The composition of UFAs regulates lipid metabolism, reduces cholesterol and triacylglycerol 
levels in the blood, and is necessary for normal function of the nervous system, heart, and retina. UFA deficit inhibits growth, causes skin lesions, and increases the risk of infections [3]. At present, due to the fact that $\omega-6$ and $\omega-3$ fatty acids are consumed in inadequate proportions, in a large number of developed countries there is an increasing incidence of diet-dependent diseases of affluence, e.g., obesity, hypertension, atherosclerosis, cholesterolemia, and some cancers [4-6]. According to the data provided in reference publications, the optimal ratio between $\omega-6$ and $\omega-3$ fatty acids should range from 2:1 to 3:1 [6,7]. Using raw camelina, linseed, peanut, or rapeseed oils in a diet has beneficial effect on the lipid profile because it reduces the concentrations of LDL cholesterol and its fractions, but does not affect the concentration of HDL cholesterol.

Vegetable oils, including camelina oil, are important products in a well-balanced everyday diet not only because of their high content of energy, vitamins, UFAs, and phytosterols, but also because of the high content of bioactive antioxidants accompanying triacylglycerols. Apart from vitamins $\mathrm{A}$ and $\mathrm{E}$, these are phenolic compounds (including phenolic acids and flavonoids), tocopherols, phytosterols, carotenoid pigments, and phospholipids. All these compounds protect unsaturated fatty acids in oil from oxidation. When these bioactive compounds contained in cold-pressed oils are consumed without being processed, they are beneficial to human health $[8,9]$. Polyphenols are important components of camelina oil as they have multidirectional functions. Furthermore, they affect taste and color, exhibit antioxidative activity, stabilize fats and other labile food ingredients. On the other hand, they act on the human organism as antioxidants. Apart from the aforementioned substances related to lipids, cold-pressed oil may also contain unfavorable components, e.g., antioxidation products, toxic trace elements, and pesticides [10].

In 2006 camelina oil was registered as a traditional product in Greater Poland Voivodeship, which is produced only by pressing at low temperatures, and can be consumed as unrefined oil. Currently, there is an increasing interest in Camelina sativa due to its tolerance to unfavorable soil and climatic conditions as well as its high resistance to diseases and pests [11,12]. Camelina maintains the same productivity level even at low rainfall and poor soil fertility [13]. Due to the low agronomic requirements of camelina scientists are becoming increasingly interested in using this plant for feeding people and animals. They also want to use camelina oil to produce bioenergy.

Research on the production of oil from other camelina cultivars than the ones which have been grown in Poland so far is justified by the fact that pilot experiments have found significant differences in the content of bioactive compounds between spring and winter cultivars and within these two types [14]. The aim of this study was to determine the qualitative and quantitative profiles of bioactive compounds in cold-pressed camelina oil and pomace, and to compare them with their content in seeds. The transmission of bioactive compounds to oil and pomace was tested in relation to their content in seeds. Three spring genotypes and one winter cultivar of camelina were analyzed.

\section{Materials and Methods}

\subsection{Plant Material}

Three spring genotypes and one winter cultivar of Camelina sativa were analyzed. In 2013, the Omega spring cultivar was registered in the National Plant Breeders' Rights (PBR) in Poland. The Luna winter cultivar was registered in 2012. Both cultivars were bred at the Department of Plant Genetics and Breeding, Poznań University of Life Sciences, Poland. The spring genotypes: Hoga and CSS-CAM 25 came from the US National Plant Germplasm System (NPGS). The Hoga genotype (PI 650150) was collected in Denmark. The CSS-CAM 25 genotype (PI 650154) was collected in the former Soviet Union. The NPGS received both genotypes in 1993.

\subsection{Field Test}

A field experiment on the genotypes was conducted in a randomized block design at the ARS Dłoń, Poznań University of Life Sciences, Poland ( $\left.51^{\circ} 41^{\prime} 23.835^{\prime \prime} \mathrm{N} 17^{\circ} 4^{\prime} 1.414^{\prime \prime} \mathrm{E}\right)$. There were three 
replications. The plot area was $15 \mathrm{~m}^{2}$. Camelina was seeded at a depth of $15 \mathrm{~mm}$ using a small plot drill. Winter Camelina cultivar was sown on 26 September 2016 while spring cultivars were sown 28 March 2017. All Camelina cultivars were sown at a rate $5 \mathrm{~kg} / \mathrm{ha}$. The field management followed standard agricultural practice. Diseases and pests were not combated. The plants were left standing in the field until they were completely ripe. All cultivars were combine-harvested (Hege 125) after reaching full maturity. Spring Camelina cultivars were harvested on 18 July 2017; winter cultivar-20 July 2017. The seed moisture was $9 \%$.

\subsection{Oil Pressing}

The implementation of the project under EUREKA international scientific programme ' $E$ !4018 CAMELINA-BIOFUEL' resulted in the construction of a set of machinery for effective pressing of oil from Camelina sativa seeds. The machinery was constructed at the Industrial Institute of Agricultural Engineering, Poznań, Poland. The set consisted of an expeller, crusher, and screw conveyor, which allowed continuous cold pressing of oil from seeds. After an initial start-up test, which was supposed to warm up the press so that it would operate at a steady temperature, the screw conveyor hopper was filled with a portion of seeds $(5 \mathrm{~kg})$. Their moisture was about $9 \%$. The seeds were crushed in the $0.2 \mathrm{~mm}$ slot of the crusher. During the entire period of the experiment, the average capacity of the crusher was $60 \mathrm{~kg} \cdot \mathrm{h}^{-1}$. The maximum capacity of the crusher was $75 \mathrm{~kg} \cdot \mathrm{h}^{-1}$. The average efficiency of the process of pressing oil from whole seeds was $69 \%$. The oil from all the samples subjected to analysis was pressed at the same time-about one month after the seeds had been harvested. Immediately after pressing the oil, seeds, and pomace were subjected to physicochemical analyses.

\subsection{Content of Phenolic and Flavonoids Compounds}

Samples weighing $10 \mathrm{~g}$ were collected for analyses of phenolic compounds. They were ground in a laboratory mill (WŻ-1). The samples subjected to analyses weighed $0.20 \mathrm{~g}$. They were placed in sealed $17 \mathrm{~mL}$ culture test tubes and subjected to alkaline and acid hydrolyses. Distilled water $(1 \mathrm{~mL})$ and $4 \mathrm{~mL}$ of $2 \mathrm{M}$ aqueous sodium hydroxide were added to the test tubes before alkaline hydrolysis. The test tubes were sealed tightly and heated in a water bath at $95{ }^{\circ} \mathrm{C}$ for $30 \mathrm{~min}$. After cooling (approx. $20 \mathrm{~min})$ the test tubes were neutralized with $2 \mathrm{~mL}$ of $6 \mathrm{M}$ aqueous hydrochloric acid solution $(\mathrm{pH}=2)$. Next, the samples were cooled in water with ice. Phenolic acids were extracted from the inorganic phase using diethyl ether $(2 \times 2 \mathrm{~mL})$. The resulting ether extracts were transferred into $8 \mathrm{~mL}$ vials. Next, acid hydrolysis was carried out. For this purpose the aqueous phase was supplemented with $3 \mathrm{~mL}$ of $6 \mathrm{M}$ aqueous hydrochloric acid solution. The test tubes were sealed tightly and heated in a water bath at $95{ }^{\circ} \mathrm{C}$ for $30 \mathrm{~min}$. After being cooled in water with ice the samples were extracted with diethyl ether $(2 \times 2 \mathrm{~mL})$. The resulting ether extracts were transferred into $8 \mathrm{~mL}$ vials. They were then evaporated to dryness in a stream of nitrogen. Before analyses the samples were dissolved in $1 \mathrm{~mL}$ of methanol. An Acquity H class UPLC system equipped with a Waters Acquity PDA detector (Waters, Milford, MA, USA) was used for the analyses. An Acquity UPLC ${ }^{\circledR}$ BEH C18 column $(100 \mathrm{~mm} \times 2.1 \mathrm{~mm}$, particle size $1.7 \mu \mathrm{m})$ (Waters, Dublin, Ireland) was used for chromatographic separation. The composition of the mobile phase of the gradient elution was as follows: A, acetonitryl with $0.1 \%$ formic acid; and B, $1 \%$ aqueous formic acid mixture $(\mathrm{pH}=2)$. The concentrations of phenolic compounds were measured using an internal standard at wavelengths of $\lambda=320 \mathrm{~nm}$ and $280 \mathrm{~nm}$. Compounds were identified by comparing the peak retention time with the standard retention time and by adding a specific amount of the standard to the samples and repeating the analysis. The detection level was $1 \mu \mathrm{g} / \mathrm{g}$. The retention times of assayed acids were as follows: kaempferol $6.11 \mathrm{~min}$, gallic acid $8.85 \mathrm{~min}$, vanillic acid $9.71 \mathrm{~min}$, luteolin $11.89 \mathrm{~min}$, protocatechuic acid $12.23 \mathrm{~min}$, apigenin $16.43 \mathrm{~min}$, catechin $18.09 \mathrm{~min}$, 4-hydroxybenzoic acid $19.46 \mathrm{~min}$, chlorogenic acid $21.56 \mathrm{~min}$, caffeic acid $26.19 \mathrm{~min}$, syringic acid $28.05 \mathrm{~min}$, naringenin $31.22 \mathrm{~min}$, vitexin $35.41 \mathrm{~min}$, rutin $38.11 \mathrm{~min}$, quercetin $39.58 \mathrm{~min}$, p-coumaric acid $40.20 \mathrm{~min}$, ferulic acid $46.20 \mathrm{~min}$, sinapic acid $48.00 \mathrm{~min}$, and t-cinnamic acid $52.40 \mathrm{~min}$. 


\subsection{Content of Carotenoids}

Carotenoids were isolated and their quantity in camelina seed samples was measured by means of Acquity ultra-high performance liquid chromatography (Waters, USA) without saponification. Carotenoid extracts were isolated from crushed camelina seeds $(0.4 \mathrm{mg})$, which were ground with a mixture of acetone and petroleum ether (1:1). When the plant tissue was separated, the acetone and hydrophilic fraction were removed from the extract by washing with water. The procedure resulted in an ether extract with a mixture of carotenoid pigments. The extract was concentrated in a vacuum evaporator at $35^{\circ} \mathrm{C}$ until the oily content was left. Next, it was dissolved in $2 \mathrm{~mL}$ of methanol (Merck Millipore, Poland) and subjected to chromatographic analysis. The content of lutein, zeaxanthin and $\beta$-carotene was measured by means of Acquity ultra-high performance liquid chromatography (Waters, USA) with a PDA 2998 detector (Waters, USA) with a 600E pump, 7725i rheodyne injector and RP-18 Atlantis T3 column, $3 \mu \mathrm{m}, 4,6 \times 150 \mathrm{~mm}$. The following solvents were used for elution: A, HPLC methanol; B, water; and C, tert-butyl methyl ether (TBME). The gradient was applied at a flow rate of $0.4 \mathrm{~mL} / \mathrm{min}$. The column and samples were regulated using a thermostat. The column temperature was $30^{\circ} \mathrm{C}$, whereas the temperature of the samples was $10^{\circ} \mathrm{C}$. During the analysis the solutions were degassed in a degasser (Waters). The injection volume was $10 \mu l$. The analysis was conducted at a wavelength of $\lambda=445 \mathrm{~nm}$. The compounds were identified by their spectra ranging from 200 to $600 \mathrm{~nm}$ and by comparing their retention times with standards.

\subsection{FAME (Fatty Acid Methyl Esters) Analysis}

The fatty acid profile of the cultivars was determined to characterize the lipid fraction as a potential source of flavor/volatile compounds. Fatty acids were extracted with the method described by Young [15]. Samples containing $100 \mathrm{mg}$ of ground seeds were placed in $17 \mathrm{~mL}$ culture tubes, suspended in $2 \mathrm{~mL}$ of methanol, treated with $0.5 \mathrm{~mL}$ of $2 \mathrm{M}$ aqueous sodium hydroxide, and sealed tightly. The culture tubes were then placed in $250 \mathrm{~mL}$ plastic bottles, sealed tightly and placed inside a microwave oven (Model AVM 401/1WH; Whirlpool, Bromma, Sweden) operating at $2450 \mathrm{MHz}$ and $900 \mathrm{~W}$ maximum output. The samples were irradiated $(370 \mathrm{~W})$ for $20 \mathrm{~s}$. After about $5 \mathrm{~min}$ they were irradiated for another $20 \mathrm{~s}$. After $15 \mathrm{~min}$, the contents of the culture tubes were neutralized with $1 \mathrm{M}$ aqueous hydrochloric acid. $\mathrm{MeOH}(2 \mathrm{~mL})$ was added and extraction was carried out with pentane (3-4 mL) within the culture tubes. The combined pentane extracts were evaporated to dryness in a nitrogen stream. Next, the extracts were methylated with a mixture of anhydrous methanol and sulphuric acid $(1: 5, v / v)$. Methanol $(0.5 \mathrm{~mL})$ and then a $0.15 \mathrm{~mL}$ methanol/sulfuric acid mixture (1:5, $v / v)$ were added to the extract containing lipids. The samples were heated at $70{ }^{\circ} \mathrm{C}$ for $15 \mathrm{~min}$. After the solution had been cooled, $0.5 \mathrm{~mL}$ of $\mathrm{n}$-hexane was added, followed by the addition of a sufficient amount of water to form two layers. The upper hexane layer was removed and analyzed with a gas chromatograph (Agilent $5890 \mathrm{II}$, Birmingham, UK) equipped with a flame ionization detector, fitted with a Supelcowax 10 column $(30 \mathrm{~m} \times 0.25 \mathrm{~mm}$ I.D., $0.25 \mathrm{~mm}$ film thickness). The injector and detector temperatures were 220 and $240{ }^{\circ} \mathrm{C}$, respectively. The column temperature was programmed to increase from 60 to $240{ }^{\circ} \mathrm{C}$ at a rate of $110^{\circ} \mathrm{C} / \mathrm{min}$. Peaks were identified by comparing the sample peak retention times with those of known methylated fatty acid compounds.

\subsection{Statistical Analysis}

The results of the chemical analyses were analyzed statistically by means of the STATISTICA $v$ 8.0 software. Tukey's multiple comparison procedure was used to compare the contents of individual metabolites in the samples. Identical letters in rows or columns denote the lack of differences at a significance level $\alpha=0.05$. 


\section{Results and Discussion}

The seeds, oil, and pomace of four genotypes of Camelina sativa (three spring genotypes and one winter cultivar) were analyzed chemically. The quantitative profile of selected bioactive compounds was analyzed: eight flavonoid aglycons, 11 phenolic acids, and 19 fatty acids.

The contents of bioactive compounds were measured to check the distribution of individual groups of antioxidants in oil and pomace. Due to the different chemical properties, solubility, and polarity of the chemical compounds under analysis, we presume that some part of bioactive compounds cannot be co-extracted with oil. The water-soluble bioactive compounds mostly remained in the pomace. The results noted for the bioactive compounds in oil and pomace were compared with the content of bioactive compounds in the input material, i.e., seeds. Earlier investigations showed that the form of development (spring or winter) influenced the profile of bioactive compounds in seeds.

The analyses showed that in total, the seeds of the spring and winter genotypes did not differ significantly in the content of eight flavonoids (Table 1). As a result of pressing more than $80 \%$ of flavonoids entered oil, whereas $20 \%$ remained in the pomace (Figure 1). However, there were significant differences between the genotypes in the content of individual bioactive compounds. The statistical analysis showed that the biggest differences between the genotypes were noted in the content of apigenin and quercetin. The diversity in the content of these flavonoids may have been caused by internal factors affecting the genetic control of enzymes participating in synthesis and distribution, the degree of seed maturity and the cultivation method. The high content of these flavonoids in oil indicates that during the pressing process their hydrophilic glycoside forms, which can be found in plant tissues, become mostly degraded to aglycone forms, which dissolve in fats easily.

Table 1. The mean content of flavonoids in spring and winter genotypes of Camelina sativa.

\begin{tabular}{|c|c|c|c|c|c|c|c|c|}
\hline & Apigenin & Catechin & \multicolumn{2}{|c|}{ KaempherolLuteolin } & \multicolumn{2}{|c|}{ Naringenin Quercetin } & Rutin & Vitexin \\
\hline \multicolumn{9}{|c|}{ seeds (mg/kg d.m.) } \\
\hline Omega & $97.78^{b}$ & $8.34^{\mathrm{a}}$ & $51.35^{c}$ & $60.71^{c}$ & $63.88^{c}$ & $127.76^{\mathrm{d}}$ & $19.84^{\mathrm{a}}$ & $55.29^{c}$ \\
\hline Hoga & $34.82^{\mathrm{a}}$ & $51.72^{d}$ & $41.83^{\mathrm{b}}$ & $67.25^{c}$ & $31.24^{\mathrm{a}}$ & $34.27^{\mathrm{a}}$ & $21.51^{\mathrm{ab}}$ & $46.85^{b}$ \\
\hline CSS-CAM 25 & $117.56^{b}$ & $20.70^{c}$ & $24.18^{a}$ & $47.53^{b}$ & $46.12^{b}$ & $48.97^{b}$ & $25.07^{b}$ & $41.88^{b}$ \\
\hline Luna & $125.46^{\mathrm{b}}$ & $14.47^{\mathrm{b}}$ & $45.99^{b}$ & $25.88^{a}$ & $48.74^{\mathrm{b}}$ & $97.48^{c}$ & $16.76^{\mathrm{a}}$ & $25.08^{a}$ \\
\hline \multicolumn{9}{|c|}{ oil (mg/L) } \\
\hline Omega & $85.24^{b}$ & $7.26^{\mathrm{a}}$ & $48.25^{\mathrm{d}}$ & $55.25^{c}$ & $59.25^{c}$ & $119.25^{\mathrm{d}}$ & $10.41^{b}$ & $50.41^{d}$ \\
\hline Hoga & $21.25^{\mathrm{a}}$ & $49.33^{c}$ & $35.57^{\mathrm{b}}$ & $57.13^{c}$ & $25.26^{\mathrm{a}}$ & $30.41^{\mathrm{a}}$ & $4.53^{\mathrm{a}}$ & $42.53^{c}$ \\
\hline CSS-CAM 25 & $89.37^{b}$ & $18.22^{b}$ & $15.25^{\mathrm{a}}$ & $40.11^{\mathrm{b}}$ & $41.22^{\mathrm{b}}$ & $35.89^{a}$ & $7.86^{\mathrm{b}}$ & $37.86^{\mathrm{b}}$ \\
\hline Luna & $102.23^{c}$ & $10.13^{\mathrm{a}}$ & $40.12^{c}$ & $21.32^{\mathrm{a}}$ & $40.12^{b}$ & $82.33^{b}$ & $9.25^{b}$ & $21.33^{\mathrm{a}}$ \\
\hline \multicolumn{9}{|c|}{ pomace (mg/kg d.m.) } \\
\hline Omega & $11.25^{\mathrm{a}}$ & $1.13^{\mathrm{a}}$ & $2.65^{\mathrm{a}}$ & $3.52^{\mathrm{a}}$ & $3.10^{\mathrm{a}}$ & $6.55^{b}$ & $6.22^{b}$ & $3.27^{\mathrm{a}}$ \\
\hline Hoga & $12.65^{\mathrm{a}}$ & $2.16^{\mathrm{a}}$ & $4.67^{b}$ & $8.25^{c}$ & $4.11^{\mathrm{a}}$ & $2.67^{\mathrm{a}}$ & $15.45^{\mathrm{a}}$ & $4.53^{\mathrm{a}}$ \\
\hline CSS-CAM 25 & $25.45^{b}$ & $2.06^{\mathrm{a}}$ & $5.37^{\mathrm{b}}$ & $4.11^{\mathrm{b}}$ & $3.45^{\mathrm{a}}$ & $12.45^{c}$ & $17.07^{\mathrm{c}}$ & $3.17^{\mathrm{a}}$ \\
\hline Luna & $21.24^{b}$ & $3.05^{\mathrm{a}}$ & $4.07^{b}$ & $4.07^{b}$ & $5.45^{\mathrm{a}}$ & $12.33^{c}$ & $5.25^{\mathrm{b}}$ & $2.01^{\mathrm{a}}$ \\
\hline
\end{tabular}



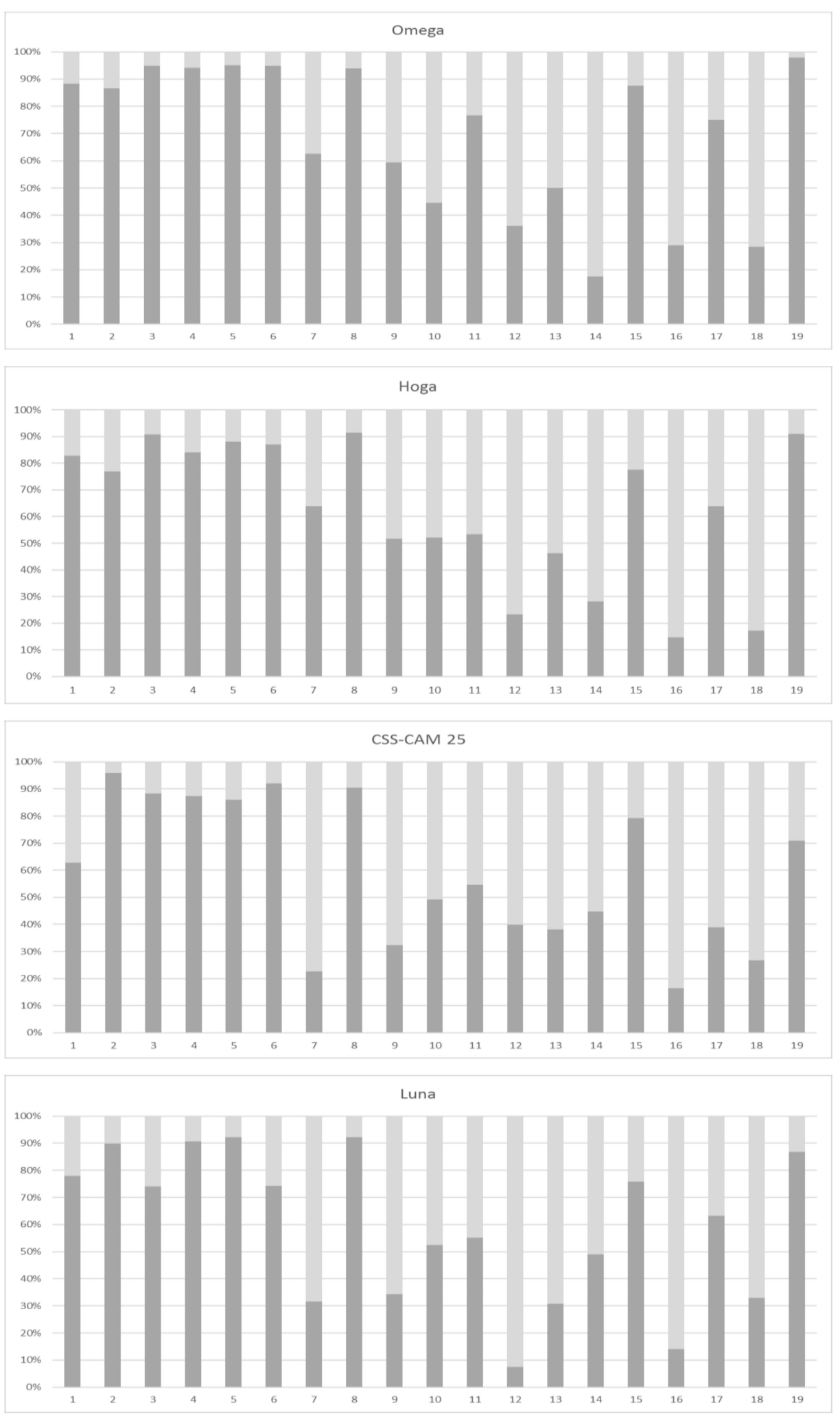

Figure 1. The flavonoid aglicons and phenolic acids composition (\%) in spring and winter genotypes of Camelina sativa: 1-Apigenin; 2-Catechin; 3-Kaempherol; 4-Luteolin; 5-Naringenin; 6-Quercetin; 7-Rutin; 8-Vitexin; 9-4-hydroxybenzoic; 10-Caffeic; 11-Chlorogenic; 12-Ferulic; 13-Gallic; 14-p-Cumaric; 15-Protocatechuic; 16-Sinapic; and 17-Syringic; 18-t-Cinnamic; 19-Vanilic.

A similar tendency was observed for phenolic acids (Table 2). There were significantly more phenolic acids in the oil than in the pomace (Figure 1). However, these proportions were different than 
those observed for flavonoids. When the content of phenolic acids in seeds and oil was compared, it turned out that on average $50 \%$ of these compounds entered oil. The rest remained in the pomace. A similar outcome was caused by the chemical properties of phenolic acids, which dissolve in water more easily than in oil. However, phenolic acids in the form of glycoside esters dissolve in fats easily. This reaction of phenolic acids is caused by their low resistance to high temperature. Although the pressing procedure did not involve heating, the ester bonds of phenolic acids, which were less durable than glycoside forms, became broken. The results showed that camelina seeds contained more esters of phenolic acids than their glycoside forms.

Table 2. The mean content of phenylcarboxylic (A) and phenylacrylic (B) acids ( $\mathrm{mg} / \mathrm{kg}$ ) in spring and winter genotypes of Camelina sativa.

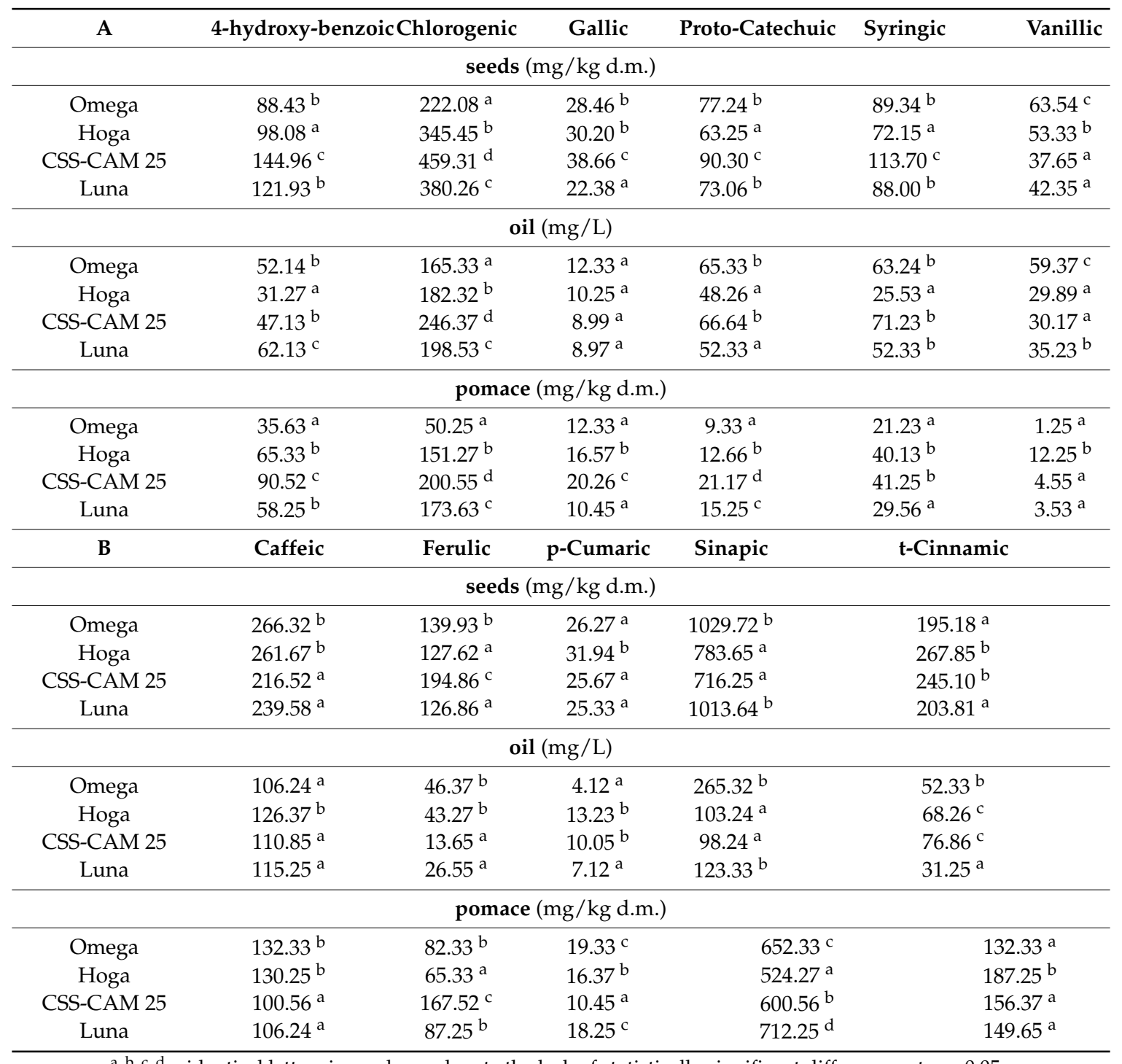

a, b, c, d__identical letters in a column denote the lack of statistically significant differences at $\alpha=0.05$.

Among all the phenolic acids under analysis, the highest contents of chlorogenic, caffeic, and sinapic acids were found both in camelina seeds and oil. There is also high content of sinapic acid in rapeseed oil (236 $\mathrm{gg} / 100 \mathrm{~g})$, but in soybean, sunflower, and grapeseed oils the content of this acid does not exceed $1.5 \mu \mathrm{g} / 100 \mathrm{~g}$ [16-18]. There was also syringic acid in camelina oil (52-71 mg/kg). Tuberoso et al. [19] studied nine different vegetable oils (cold-pressed oil from flax, grape seeds, maize, peanuts, pumpkins, rapeseeds, soybeans, sunflowers, and olives) and found syringic acid only in rapeseed 
oil $(6.8 \mathrm{mg} / \mathrm{kg})$. Most edible oils do not contain protocatechuic acid, but it can be found in camelina oil $(48-66 \mathrm{mg} / \mathrm{kg})$ and in pumpkin oil $(3.1 \mu \mathrm{g} / 100 \mathrm{~g})$ [17]. The presence of phenolic acids, whose quantitative and qualitative profile has not been tested in gold oil is very important for consumers. Raw oil influences the digestive system by preventing inflammation, relieving reflux, and lowering the acid level in the stomach. Phenolic acids have an anti-inflammatory effect.

Carotenoids were another group of bioactive compounds under analysis. Reference publications provide very scarce information on the content of carotenoids in camelina oil. So far, researchers have chiefly analyzed the total content of carotenoids or the content of $\beta$-carotene only. The results of our study showed that there was high content of $\beta$-carotene in camelina seeds and oil (Table 3). We also found lutein and zeaxanthin. As far as the latter is concerned, there was significantly higher content of this carotenoid in the Hoga genotype. The analyzed cultivars had similar levels of zeaxantin, except for the Hoga cultivar, which had 30 times higher content of this carotenoid. Similarly to the other bioactive compounds, more than $70 \%$ of fat-soluble carotenoids were extracted from camelina seeds with oil.

Table 3. The content of $\beta$-carotene, zeaxanthin, and lutein in oil, pomace, and seeds of spring and winter genotypes of Camelina sativa $(\mathrm{mg} / \mathrm{kg})$.

\begin{tabular}{cccc}
\hline & Lutein & Zeaxanthin & $\beta$-Carotene \\
\hline \multicolumn{4}{c}{ seeds (mg/kg d.m.) } \\
\hline Omega & $12.19^{\mathrm{a}}$ & $0.25^{\mathrm{a}}$ & $146.31^{\mathrm{a}}$ \\
Hoga & $16.10^{\mathrm{b}}$ & $7.09^{\mathrm{b}}$ & $133.69^{\mathrm{a}}$ \\
CSS-CAM 25 & $17.15^{\mathrm{b}}$ & $0.22^{\mathrm{a}}$ & $140.64^{\mathrm{a}}$ \\
Luna & $12.74^{\mathrm{a}}$ & $0.25^{\mathrm{a}}$ & $139.36^{\mathrm{a}}$ \\
\hline \multicolumn{4}{c}{ oil (mg/L) $^{\mathrm{y}}$} \\
\hline Omega & $8.75^{\mathrm{a}}$ & $0.21^{\mathrm{a}}$ & $140.23^{\mathrm{b}}$ \\
Hoga & $14.58^{\mathrm{b}}$ & $6.54^{\mathrm{b}}$ & $120.74^{\mathrm{a}}$ \\
CSS-CAM 25 & $15.98^{\mathrm{b}}$ & $0.19^{\mathrm{a}}$ & $131.58^{\mathrm{a}}$ \\
Luna & $9.35^{\mathrm{a}}$ & $0.18^{\mathrm{a}}$ \\
\hline \multicolumn{4}{c}{$125.69^{\mathrm{a}}$} \\
\hline Pomace (mg/kg d.m.) \\
Hoga & $3.53^{\mathrm{a}}$ & $0.05^{\mathrm{a}}$ \\
CSS-CAM 25 & $5.25^{\mathrm{a}}$ & $1.72^{\mathrm{b}}$ & $30.56^{\mathrm{a}}$ \\
Luna & $4.26^{\mathrm{a}}$ & $0.07^{\mathrm{a}}$ & $33.66^{\mathrm{a}}$ \\
\hline
\end{tabular}

$\mathrm{a}, \mathrm{b}$ _-identical letters in columns denote a lack of significant differences at a significance level of 0.05 .

The carotenoids contained in the oil, such as lutein, are beta-carotene derivatives, hence their bioavailability is higher than that of beta-carotene.

The next very important stage of the research consisted in the identification of the fatty acid profile in camelina oil. There were no statistically significant differences in the oil content between the Camelina sativa genotypes under analysis, but the values in the results of our study were lower than in reference publications (Table 4). The oil content in camelina seeds differed according to the location, i.e., $35-43 \%$ in Canada [20-22], 35-40\% in the US [23], and 37-41\% in Germany [24]. 
Table 4. The fatty acid composition (\%) in spring and winter genotypes of Camelina sativa.

\begin{tabular}{ccccc}
\hline Fatty Acid & Omega & Hoga & CSS-CAM 25 & Luna \\
\hline Seed oil content & $21^{\mathrm{a}}$ & $21^{\mathrm{a}}$ & $24^{\mathrm{a}}$ & $30^{\mathrm{a}}$ \\
myristic acid & $0.251^{\mathrm{b}}$ & 0 & $0.125^{\mathrm{a}}$ & $0.125^{\mathrm{a}}$ \\
pentadecanoic acid & 0 & 0 & 0 & 0 \\
pentadecenoic acid & 0 & 0 & 0 & 0 \\
palmitic acid (PA) & $3.513^{\mathrm{a}}$ & $3.136^{\mathrm{a}}$ & $6.022^{\mathrm{b}}$ & $3.764^{\mathrm{a}}$ \\
palmitoleic acid & $0.125^{\mathrm{b}}$ & 0 & $1.004^{\mathrm{b}}$ & 0 \\
margaric acid & 0 & 0 & 0 & 0 \\
10-heptadecenoic acid & 0 & 0 & 0.125 & 0 \\
stearic acid & $2.384^{\mathrm{b}}$ & $1.882^{\mathrm{a}}$ & $2.785^{\mathrm{b}}$ & $1.882^{\mathrm{a}}$ \\
oleic acid & $14.427^{\mathrm{b}}$ & $12.294^{\mathrm{a}}$ & $16.058^{\mathrm{c}}$ & $12.294^{\mathrm{a}}$ \\
linoleic acid (LA) & $18.316^{\mathrm{b}}$ & $14.051^{\mathrm{a}}$ & $19.821^{\mathrm{b}}$ & $14.803^{\mathrm{a}}$ \\
$\gamma$-linolenic acid (GLA) & 0 & 0 & 0.251 & 0 \\
$\alpha$-linolenic acid (ALA) & $36.883^{\mathrm{a}}$ & $35.378^{\mathrm{a}}$ & $46.041^{\mathrm{c}}$ & $39.141^{\mathrm{b}}$ \\
arachidic acid (ARA) & $0.627^{\mathrm{a}}$ & $0.502^{\mathrm{a}}$ & $1.756^{\mathrm{b}}$ & $0.878^{\mathrm{a}}$ \\
c-11-eicosenoic acid & $20.07^{\mathrm{b}}$ & $25.96^{\mathrm{c}}$ & $15.355^{\mathrm{a}}$ & $23.45^{\mathrm{b}}$ \\
c-11, 14-eicosadienoic acid & $0.878^{\mathrm{a}}$ & $1.30^{\mathrm{b}}$ & $0.502^{\mathrm{a}}$ & $1.255^{\mathrm{b}}$ \\
heneicosanoic acid & $0.125^{\mathrm{a}}$ & $0.251^{\mathrm{a}}$ & 0 & $0.251^{\mathrm{a}}$ \\
erucic acid (EU) & $3.262^{\mathrm{a}}$ & $3.889^{\mathrm{a}}$ & 0 & $3.262^{\mathrm{a}}$ \\
lignoceric acid & $0.125^{\mathrm{a}}$ & $0.202^{\mathrm{a}}$ & 0 & $0.125^{\mathrm{a}}$ \\
nervonic acid & $0.376^{\mathrm{a}}$ & $0.753^{\mathrm{b}}$ & 0 & $0.753^{\mathrm{b}}$ \\
$\sum$ SFA & $10.3^{\mathrm{a}}$ & $9.9^{\mathrm{a}}$ & $10.7^{\mathrm{a}}$ & $10.3^{\mathrm{a}}$ \\
$\sum$ MUFA & $35.0^{\mathrm{b}}$ & $39.0^{\mathrm{b}}$ & $32.5^{\mathrm{a}}$ & $36.5^{\mathrm{b}}$ \\
$\sum$ PUFA & $56.1^{\mathrm{b}}$ & $50.8^{\mathrm{a}}$ & $66.6^{\mathrm{c}}$ & $55.2^{\mathrm{b}}$ \\
EFA & $55.2^{\mathrm{a}}$ & $49.4^{\mathrm{a}}$ & $65.9^{\mathrm{b}}$ & $53.9^{\mathrm{a}}$ \\
PUFA $\omega-6 /$ PUFA $\omega-3$ & $1: 2.0^{\mathrm{a}}$ & $1: 2.5^{\mathrm{a}}$ & $1: 2.3^{\mathrm{a}}$ & $1: 2.6$ \\
\hline
\end{tabular}

SFA—saturated fatty acids, MUFA—monounsaturated fatty acids; PUFA-polyenoic fatty acids; PUFA $n$ - 6 - polyenoic fatty acids of $n-6$ family; PUFA $n-3$ - polyenic fatty acids of $n$-3 family; and EFA - essential fatty acids. ${ }^{a}$ b_identical letters in columns denote a lack of significant differences at a significance level of 0.05 .

Most genotypes had the fatty acid composition characteristic of camelina oil (Table 3), which is rich in oleic acid (18:1, 14-18\%), linoleic acid, (18:2, 15-23\%), linolenic acid (18:3, 28-40\%), and eicosenoic acid (20:1, 12-17\%) [5,25-28].

There were significant differences in the content of $\Sigma$ MUFA and $\sum$ PUFA in the CSS-CAM 25 (PI 650154) genotype, which had the lowest content of $\sum$ MUFA and the highest content of $\sum$ PUFA. The $\omega-6 / \omega-3$ ratio in all the genotypes was about 1:2. This is characteristic of camelina oil [5], which is a good source of $\omega-3$ acids (ALA). The camelina genotypes contained $35 \%$ (Hoga) to $46 \%$ (CSS-CAM 25) of $\alpha$-linoleic acid. The content of $\alpha$-linoleic acid amounted to less than $1 \%$ in olive and sunflower oils, about $8 \%$ in rapeseed and soybean oils, $10.4 \%$ in walnut oil, and up to $60 \%$ in linseed $[23,29,30]$. It is very important to enrich the diet with products containing large amounts of $\omega$-3 acids, especially due to the fact that many vegetable oils (sunflower oil, saffron oil, cottonseed oil, soybean oil) contain large amounts of $\omega-6$ acids [6].

As a result of metabolism, $\alpha$-linolenic acid (ALA) can be converted into eicosapentaenoic acid (EPA) and docosahexaenoic acid (DHA). However, the conversion of ALA into EPA and DHA depends on the ratio of ALA to LA in the food consumed [31]. High values of the $\omega-6 / \omega-3$ ratio in the diet, e.g., from 10:1 to 20:1, reduce the synthesis of linolenic eicosanoids and may stimulate inflammations [32]. In highly developed countries people's diets are usually rich in saturated acids and $\omega-6$ acids. Therefore, using camelina oil as functional food may help to reduce the $\omega-6 / \omega-3$ ratio in the diet.

Analyzing the quantitative profile of selected bioactive compounds in oil did not reveal any differences resulting from the form of cultivation of the camelina genotypes under study. However, there were differences between the genotypes. They were caused by their origin and genetic differences. The content of selected phenolic acids (syringic, vanillic, p-cumaric acids) was similar in both Polish cultivars. Apart from vanillic acid, the highest values of phenylcarboxylic acid were noted in the 
CSS-CAM cultivar, which came from the former Soviet Union. It was the only genotype where 4-hydroxybenzoic and gallic acids were not extracted with oil but most of them remained in pomace.

Camelina sativa is tolerant to unfavorable soil and climatic conditions. In addition, camelina has unique agronomic traits, which include a short vegetation period. Camelina's adaptation to vast areas of the world, high oil content combined with its unique oil composition and properties makes it a suitable oil source for the production of biofuels, jet fuel, biobased-products, feed, and food. Camelina could become an important plant for obtaining oil rich in antioxidant bioactive compounds and a sustainable source of omega-3 acids.

The presented studies indicate a significant potential for using cold pressed oils and pomace. Oils, cold-pressed, rich in naturalized antioxidants, are used for raw consumption. They can thus be considered a functional food. Significant amounts of bioactive compounds in the pomace indicate the potential of using this waste material as a source of bioactive compounds.

\section{Conclusions}

On the basis of the conducted research, significant differences in the content of bioactive compounds between seeds, pomace and oil were found. The highest content of tested compounds was found in oil, lower in seeds and the lowest in pomace. The distribution of bioactive compounds in the tested samples varied. Camelina oil is characterized by properties that enable its extensive use in the food industry.

Author Contributions: Conceptualization, D.K.-P. and K.S.-S.; methodology K.S.-S.; software, K.S.-S.; validation, K.S.-S. and B.R.; formal analysis, K.S.-S.; investigation, D.K.-P.; resources, D.K.-P.; data curation, B.R.; writing_original draft preparation, D.K.-P. and K.S.-S.; writing-review and editing, D.K-P. and K.S.-S.; visualization, D. K.-P. and K.S.-S.; supervision, D.K.-P.; project administration, D.K.-P.; funding acquisition, D.K.-P.

Funding: This research was funded by Poznan University of Life Sciences, grant number 508.102.00 and "The APC was funded by Poznan University of Life Sciences". This publication is being co-financed by the framework of Ministry of Science and Higher Education program as "Regional Initiative Excellence" in years 2019-2022, project no. 005/RID/2018/19.

Conflicts of Interest: The authors declare no conflict of interest.

\section{References}

1. Rosiak, E. Spożycie tłuszczów w Polsce i Unii Europejskiej. Proble. World Agric. Problemy Rolnictwa Światowego 2016, 16, 279-288.

2. Fan, L.; Eskin, N.A.M. Camelina oil: Chemistry, properties and utilization. Recent Res. Dev. Lipids 2013, 9, 125-137.

3. Sikorski, Z.E. Interakcje składników żywności. W: Chemia żywności. T. III. Odżywcze i zdrowotne właściwości składników żywności. Red. Z.E. Sikorski; WN-T: Warszawa, Poland, 2007; pp. 204-222.

4. Cosima, A.; Konkel, A.; Fischer, R.; Schunck, W.-H. Cytochrome P450-dependent metabolism of $\omega-6$ and $\omega-3$ long-chain polyunsaturated fatty acids. Pharmacol. Rep. 2010, 62, 536-547.

5. Belayneh, H.D.; Wehling, R.L.; Cahoon, E.; Ciftci, O.N. Extraction of omega-3-rich oil from Camelina sativa seed using supercritical carbon dioxide. J. Supercrit. Fluids 2015, 104, 153-159. [CrossRef]

6. Simopoulos, A.P. An increase in the omega-6/omega-3 fatty acid ratio increases the risk for obesity. Nutrients 2016, 2, 128. [CrossRef]

7. Callaway, J.; Schwab, U.; Harvima, I.; Halonen, P.; Mykkänen, O.; Hyvönen, P.; Järvinen, T. Efficacy of dietary hempseed oil in patients with atopic dermatitis. J. Dermatol. Treat. 2005, 16, 87-94. [CrossRef] [PubMed]

8. Edge, R.; McGarvey, D.J.; Truscott, T.G. The carotenoids as anti-oxidants-A review. J. Photochem. Photobiol. B 1997, 41, 189-200. [CrossRef]

9. Palermo, N.E.; Holick, M.F. Vitamin D, bone health, and other health benefits in pediatric patients. J. Pediat. Rehabil. Med. 2014, 7, 179-192.

10. Choo, W.S.; Birch, J.; Dufour, J.P. Physicochemical and quality characteristics of cold-pressed flaxseed oils. J. Food Compos. Anal. 2007, 20, 202-211. [CrossRef] 
11. Sharma, G.; Kumar, V.D.; Haque, A.; Bhat, S.R.; Prakash, S.; Chopra, V.L. Brassica coenspecies: A rich reservoir for genetic resistance to leaf spot caused by Alternaria brassicae. Euphytica 2002, 125, 411-417. [CrossRef]

12. Henderson, A.E.; Hallett, R.H.; Soroka, J.J. Prefeeding behaviour of the crucifer flea beetle, Phyllotreta cruciferae, on host and nonhost crucifers. J. Insect Behav. 2004, 17, 17-39. [CrossRef]

13. Lu, C.; Napier, J.A.; Clemente, T.E.; Cahoon, E.B. New frontiers in oilseed biotechnology: Meeting the global demand for vegetable oils for food, feed, biofuel, and industrial applications. Curr. Opin. Biotechnol. 2011, 22, 252-259. [CrossRef] [PubMed]

14. Kurasiak-Popowska, D.; Stuper-Szablewska, K.; Nawracała, J. Olej rydzowy jako naturalne źródło karotenoidów dla przemysłu kosmetycznego [Camelina oil as a natural source of carotenoids for the cosmetic industry]. Przem. Chem. 2017, 96, 2077-2080.

15. Young, J.C. Microwave-assisted extraction of the fungal metabolite ergosterol and total fatty acids. J. Agric. Food Chem. 1995, 4311, 2904-2910. [CrossRef]

16. Cai, R.; Arntfield, S.D. A rapid high-performance liquid chromatographic method for the determination of sinapine and sinapic acid in canola seed and meal. J. Am. Oil Chem. Soc. 2001, 78, 903-910. [CrossRef]

17. Siger, A.; Nogala-Kalucka, M.; Lampart-Szczapa, E. The content and antioxidant activity of phenolic compounds in cold-pressed plant oils. J. Food Lipids 2008, 15, 137-149. [CrossRef]

18. Siger, A.; Nogala-Kalucka, M.; Lampart-Szczapa, E.; Hoffmann, A. Phenolic compound contents in new rape varieties. Rośliny Oleiste/Oilseed Crops 2004, 25, 263-274. (In Polish)

19. Tuberoso, C.I.G.; Kowalczyk, A.; Sarritzu, E.; Cabras, P. Determination of antioxidant compounds and antioxidant activity in commercial oilseeds for food use. Food Chem. 2007, 103, 1494-1501. [CrossRef]

20. Gugel, R.K.; Falk, K.C. Agronomic and seed quality evaluation of Camelina sativa in western Canada. Can. J. Plant Sci. 2006, 1047-1058. [CrossRef]

21. Urbaniak, S.D.; Caldwell, C.D.; Zheljazkov, V.D.; Lada, R.; Luan, L. The effect of cultivar and applied nitrogen on the performance of Camelina sativa L. In: The Maritime Provinces of Canada. Can. J. Plant Sci. 2008, 88, 111-119. [CrossRef]

22. Urbaniak, S.; Caldwell, C.; Zheljazkov, V.; Lada, R.; Luan, L. The effect of seeding rate: Seeding date and seeder type on the performance of Camelina sativa L. in the Maritime Provinces of Canada. Can. J. Plant Sci. 2008, 88, 501-508. [CrossRef]

23. Budin, J.T.; Breene, W.M.; Putman, D.H. Some compositional properties of camelina (Camelina sativa L. Crantz) seeds and oils. J. Am. Oil Chem. Soc. 1995, 72, 309-315. [CrossRef]

24. Zubr, J.; Matthäus, B. Effects of growth conditions on fatty acids and tocopherols in Camelina sativa oil. Ind Crops Prod. 2002, 15, 155-162. [CrossRef]

25. Zubr, J. Oil-seed crop: Camelina sativa. Ind. Crops Prod. 1997, 6, 113-119. [CrossRef]

26. Singh, B.K.; Bala, M.; Rai, P.K. Fatty acid composition and seed meal characteristics of Brassica and allied genera. Natl. Acad. Sci. Lett. 2014, 373, 219-226. [CrossRef]

27. Berti, M.; Gesch, R.; Eynck, C.; Anderson, J.; Cermak, S. Camelina uses, genetics, genomics, production, and management. Ind. Crops Prod. 2016, 94, 690-710. [CrossRef]

28. Popa, A.L.; Jurcoane, Ș.; Dumitriu, B. Camelina sativa oil-a review. Sci. Bull. Ser. F Biotechnol. 2017, 21, 233-238.

29. Nettleton, J.A. $\omega-3$ Fatty acids: Comparison of plant and seafood sources in human nutrition. J. Am. Diet. Assoc. 1991, 91, 331-337.

30. Hui, Y.H. Bailey's Industrial Oil and Fat Products, 5th ed.; Wiley: New York, NY, USA, 1996; Volume 2.

31. Gebauer, S.K.; Psota, T.L.; Harris, W.S.; Kris-Etherton, P.M. $n$-3 Fatty acid dietary recommendations and food sources to achieve essentiality and cardiovascular benefits. Am. J. Clin. Nutr. 2006, 83 (Suppl. 6), 1526-1535. [CrossRef]

32. Tapiero, H.; Couvreur, G.N.; Ba, P.; Tew, K.D. Polyunsaturated fatty acids PUFA and eicosanoids in human health and pathologies. Biomed. Pharmacother. 1999, 56, 215-222. [CrossRef]

(C) 2019 by the authors. Licensee MDPI, Basel, Switzerland. This article is an open access article distributed under the terms and conditions of the Creative Commons Attribution (CC BY) license (http:/ / creativecommons.org/licenses/by/4.0/). 